\title{
ANALISIS PENERAPAN PSAK 109 TENTANG AKUNTANSI ZAKAT, INFAQ, DAN SEDEKAH PADA BADAN AMIL ZAKAT NASIONAL KABUPATEN MAJENE
}

\author{
Analysis of The Implementation of PSAK 109 Concerning \\ Accounting For Zakat, Infaq, And Sedekah By National Amil \\ Agency of Majene Regency
}

\author{
Sitti Hadijah \\ Email: hadijah@unsulbar.ac.id \\ Prodi Akuntansi Fakultas Ekonomi Unsulbar \\ J1.Prof. Baharuddin Lopa, S Talumung Majene Sulawesi Barat
}

\begin{abstract}
ABSTRAK
Penelitian ini bertujuan untuk mengetahui penerapan akuntansi zakat, infaq, dan sedekah berdasarkan PSAK 109 kepada Badan Amil Zakat Nasional Kabupaten Majene tahun 2014-2016. Data yang digunakan adalah data primer dan data sekunder. Teknik pengambilan data dilakukan dengan wawancara dan studi dokumentasi. Metode analisis yang digunakan adalah analisis deskriptif kualitatif. Hasil penelitian ini menunjukkan pengelolaan Badan Amil Zakat Nasional Kabupaten Majene tahun 2014-2016, untuk pengelolaan keuangan yang di dalamnya terdapat pengakuan, pengukuran, penyajian dan pengungkapn belum sepenuhnya mengarah pada implementasi yang sesuai dengan aturan yaitu PSAK 109 yang mengatur tentang Akuntansi zakat dan Infaq/ sedekah.
\end{abstract}

\section{Kata Kunci: PSAK 109 Zakat, Infaq, dan Sedekah}

\section{ABSTRACT}

This study aims to find out application of zakat, infaq, and alms accounting based on PSAK 109 to Majene Regency National Zakat Amil Agency 2014-2016. The data used are primary data and secondary data. The data collection technique is done by interview and documentation study. The analytical method used is qualitative descriptive analysis. The results of this study indicate the management of the Amil National Zakat Agency in Majene Regency for 20142016, for financial management which includes recognition, measurement, presentation and disclosure, it has not yet fully led to the implementation in accordance with the rules, namely PSAK 109 which regulates Accounting for Zakat and Infaq/ Sedekah.

Keywords: PSAK, zakat, infaq, and alms 


\section{PENDAHULUAN}

Perekonomian suatu bangsa akan selalu menjadi standar dalam menilai Kesejahteraan masyarakat setempat. Semakin berkembangnya perekonomian akan semakin mampu menghantarkan masyarakatnya ke dalam kehidupan yang aman dan sejahtera, begitu pula semakin merosot perekonomian suatu bangsa akan sangat berpengaruh kehidupan masyarakat yang ada di dalamnya

Sebagaimana kita ketahui bahwa ada tiga kekuatan besar di dunia yang sangat mempengaruhi sistem perekonomian yaitu sistem ekonomi Sosialis, sistem ekonomi Kapitalis, dan sistem ekonomi Islam. Ketiga aliran ini sudah pernah di terapkan di masing-masing negara, seperti ekonomi kapitalis yang semua negara di dunia menggunakan sistem ekonom kapitalis seperti yang ada sekarang. Dengan penerapan sistem ekonom kapitalis sebagian besar masyarakat menyadari begitu banyak kekurangan yang terdapat di dalamya, contoh yang bisa kita lihat adalah yang kaya semakin kaya dan miskin semakin miskin, hanya para pemilik modal yang bisa tetap bertahan dengan menggunakan sistem ekonomi kapitalis. Seiring berjalannya waktu masyarakat seolah-olah mencari sistem yang terbaik di bandingkan dengan dua sistem yang ada, yakni sistem ekonomi Islam.

Zakat, infaq, dan sedekah adalah bagian penting dan sudah sangat jelas dalam sistem ekonomi Islam. Berdasarkan ketentuan Undang-Undang Zakat Nomor 23 Tahun 2011 bagian Kelima pasal 29 ayat 1 bahwa BAZNAS kabupaten/kota wajib menyampaikan laporan pelaksanaan pengelolaan zakat, infak, sedekah, dan sosial keagamaan lainnya kepada BAZNAS provinsi dan pemerintah daerah secara berkala.Forum Zakat bersama dengan Ikatan Akuntan Indonesia (IAI) menyusun akutansi zakat pada tahun 2007. Pada tahun 2008 IAI menyelesaikan PSAK No.109 tentang Akuntansi Zakat.Hal ini diharapkan dapat terwujudnya keseragaman pelaporan,sehingga publik dapat membaca laporan akuntansi Lembaga Amil Zakat serta mengawasi pengelolaannya. Selain itu penerapan PSAK 109 ini juga bertujuan memastikan bahwa organisasi Lembaga Amil Zakat telah memakai prinsip-prinsip syariah, dan seberapa jauh lembaga Lembaga Amil Zakat memiliki tingkat kepatuhan menerapkannya. PSAK 109 yang mengatur akuntansi zakat dan infak/sedekah, di dalamnya termuat definisi-definisi, 
pengakuan dan pengukuran, penyajian, serta pengungkapan hal-hal yang terkait dengan kebijakan penyaluran hingga operasionalisasi zakat dan infak/sedekah.

Badan Amil Zakat Nasional Kabupaten Majene telah melakukan pengelolaan dan pendistribusian dengan baik, namun masih belum diketahui apakah pencatatan dan pelaporan yang dilakukan oleh Badan Amil Zakat Nasional Kabupaten Majene telah sesuai dengan PSAK 109 atau belum. Untuk mengetahui hal ini perlu dibuktikan informasi tersebut dan dianalisis lebih lanjut termasuk mengenai penerapan PSAK 109 pada Badan Amil Zakat Nasional Kabupaten Majene dari tahun 2014 sampai dengan tahun 2016. Berdasarkan informasi tersebut, maka penulis ingin mengetahui sejauh mana penerapan akuntansi zakat dengan mengacu pada PSAK nomor 109 yakni zakat, infaq, dan sedekah.

\section{METODE PENELITIAN}

Jenis data yang ada dalam penelitian ini yakni data primer dan data sekunder. Data primer peneliti peroleh melalui wawancara mendalam dari sumber data. Keseluruhannya dipilih secara sengaja (purposive) karena dengan pertimbanganpertimbangan tertentu, yaitu peneliti ingin mengungkap secara empirik dan mendalam tentang pengelolaan dan penerapan PSAK 109 tentang akuntansi zakat oleh Badan Amil Zakat Nasional (BAZNAS) Kabupaten Majene tahun 2014-2016.

Sumber data lainnya adalah sumber data sekunder berupa dokumen. Dokumendokumen tersebut dapat berupa undang-undang, peraturan pemerintah, dan laporan keuangan tahun 2014 sampai dengan tahun 2016.Fokus Penelitian ini, yakni: Penerapan Akuntansi berdasarkan PSAK 109 Zakat, Infaq, dan sedekah. Untuk mendapatkan data yang dibutuhkan dalam penelitian ini, maka peneliti melakukan kegiatan Wawancara mendalam dan telaah dokumentasi

\section{HASIL DAN PEMBAHASAN}

Berdasarkan hasil wawancara yang di lakukan kepada pengurus Baznas Kab. Majene yang fokus pertanyaannya berhubungan dengan Penerapan zakat sesuai dengan PSAK 109 tahun 2014-2016 di dapatkan hasil sebagai berikut : 
Wawancara kepada ketua, wakil ketua 1 dan wakil ketua II

1. Bagaimana pengelolaan Zakat, Infaq, dan Sedekah di tahun 2014-2016 pada Baznas Kab. Majene

“ untuk tahun 2014-2016, begitu pula tahun 2017 belum menggunakan laporan keuangan sebagaiman mestinya yakni sesuai dengan PSAK 109 ( Zakat, infaq, dan sedekah) nanti mulai di siapkan pada tahun 2017 dan implementasi tahun 2018" ( wawancara tanggal 15 Mei 2018 )

2. Bagaimana pengelolaan keuangan Basnaz Kab. Majene tahun 2014-2016

“Pengelolaan selama tahun 2014-2016 tidak ada perubahan signifikan dan belum menggunakan pengelolaan sesuai dengan PSAK 109, nanti pada tahun 2017 baru mulai di siapkan untuk mengikuti aturan yang di berlakukan yang sudah mulai di implementasikan pada tahun berjalan yakni tahun 2018 tentunya dengan senantiasa bersinergi pemda dan Pemprov.

" Sekalipun seluruhnya belum menggunaan PSAK 109 akan tetapi pengakuan dan pengukuran zakat Kab. Majene tetap di jalankan tidak jauh berbeda dengan apa yang terdapat di dalam Peraturan tersebut “

( Wawancara tanggal 15 Mei 2018)

3. Apa yang menjadi penyebab sehingga PSAK 109 tidak cepat di terapkan di Baznas Kab. Majene, sedangkan PSAK 109 sudah lama di keluarkan oleh pemerintah ( PSAK)

" keterbatasan sumber daya manusia menjadi penyebab utama tidak cepatnya di terapkan PSAK 109 zakat, infaq, dan sedekah disamping juga membutuhkan sosialiasi yang baik dari pemerintah guna untuk memahami lebih jauh tentang PSAK 109, dan kami memahami betapa pentingnya aturan tersebut sehingga Baznas Kab. Majene melakukan kunjungan kebeberapa Baznas di wilayah Sul-Sel dan di luar Sulawesi untuk melihat perkembangan lebih jauh tentang penerapan PSAK 109. Di samping itu dukungan dari pemda sangat dibutuhkan berupa dana untuk menjalankan kegiatan Operasional sehingga pelayanan kepada masyarakat terkait pengelolaan zakat bisa berjalan dengan baik sesuai yang di harapkan"

(wawancara tanggal 15 Mei 2018 )

4. Apakah Baznas Kab. Majene menyajikan dana zakat, dana infaq/sedekah secara terpisah laporan posisi keuangan

“ kalau tahun 2014-2016 belum di pisahkan masih dalam satu penggabungan laporan sedangkan tahun berjalan sudah di pisah masingmasing laporan keuangannya begitu pula dengan rekening zakat, infaq/ sedekah. 
“ tahun 2014-2016 laporan keuangannya di buat sebagai mana standarisasi laporan keuangan, tapi apabila di bandingkan laporan keuangan pada tahun 2017 di tahun ini sudah terinci dengan baik sebagaiman dengan tuntutan pemerintah. Walaupun ada kelebihan yang terdapat di tahun 2014-2016 di tahun ini lebih flexible dalam pembagian dana sesuai yang di anggap perlu karena belum ada penentuan pos-pos penggunaan dana, misalnya pos nya di Ekonomi lemah maka memang harus di salurkan langsung tidak bisa di alihkan ke pos yang lain berbeda dengan tahun 2017 karena sudah mulai berjalann sesuai RKAT maka Baznas menggunakan dana sesuai dengan pos-pos yang telah di tentukan" ( wawancara tanggal 15 Mei 2018 )

6. Bagaimana tim audit yang terdapat di Baznas Kab. Majene

" Tim audit ada 2 yaitu audit syaria dan audit eksternal, audit syariah dari kementrian agama sedangkan audit eksternal dari Pemda( Inspektorat)" ( wawancara tanggal 07 Juli 2018)

7. Apakah ada pendanaan langsung dari pusat ke daerah?

" Sebelumnya ada pertama itu 20 juta, 2013 naik menjadi 40 juta sedangkan tahun 2014 sampai selanjutnya sudah tidak ada lagi, penjelasannya katanya di satukan bantuan pendanaannya dari Kementrian agama" (wawancara tanggal 07 Juni 2018)

8. Apakah zakat yang di salurkan kepada mustahik, termasuk amil di akui sebagai pengurangan dana zakat?

"Ya pada saat zakat telah di keluarkan baik dalam bentuk kas maupun aset non kas seperti peralatan, mesin di akui sebagai pengurangan dana zakat karena telah di distribusikan kepada 8 Asnaf sesuai dengan prinsip syariah( wawancara tanggal 17 Juli)

9. Bagaimana besaran jumlah zakat yang masuk di Baznas

"Kalau dirata ratakan pemasukan dalam satu bulan zakat, infaq dan sedekah di kisaran 70 juta per bulan, tapi kalau kesadaran masyarakat meningkat dan di berlakukan zakat profesi maka bisa pemasukan sekitar 400 juta perbulannya". Nilai ini tergolong sangat kecil di bandingkan dengan tingginya data jumlah masyarakat

( wawancara tanggal 07 Juni 2018)

10. Apakah penerimaan zakat di akui pada saat kas atau aset non kas di terima

"Ya penerimaan zakat diakui pada saat kas di terima di Baznaz

( wawancara tanggal 17 Juli 2018)

11. Bagaimana penentuan jumlah presentase bagian untuk masing-masing mustahik

"Penentuannya di tentukan oleh amil sesuai dengan prinsip syariah, kewajaran, etika contoh wajib di peruntukkan kepada 8 asnaf (wawancara 17 Juli 2018) 
12. Apakah dana infaq/sedekah yang di terima dapat berupa kas ata aset non kas

“ Infaq/sedekah yang di terima dapat berupa kas atau aset non kas. Aset yang di terima dapat berupa aset lancar atau tidak lancar

13. Bagaimana cara penentuan nilai penerimaan infaq dan sedekah

" penentuan nilai wajar aset nonkas yang diterima menggunakan harga pasar

PEMBAHASAN DAN HASIL PENELITIAN

Tabel. 1 Kesesuaian Pengelolaan Keuangan dengan PSAK 109

\begin{tabular}{|c|c|c|c|c|}
\hline $\mathrm{NO}$ & INDIKATOR & SESUAI & $\begin{array}{l}\text { TIDAK } \\
\text { SESUAI }\end{array}$ & KETERANGAN \\
\hline 1 & 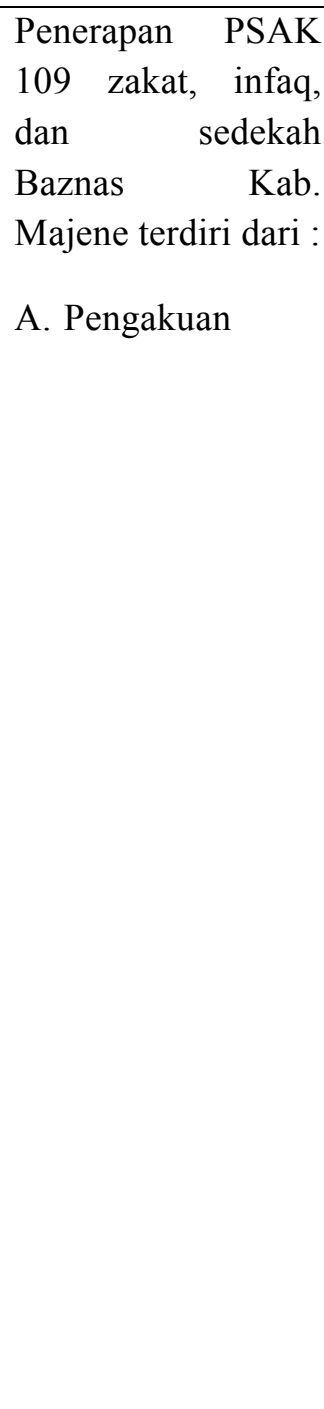 & $\sqrt{ }$ & & $\begin{array}{l}\text { a. Penerimaan zakat diakui pada saat } \\
\text { kas atau aset non kas di terima } \\
\text { b. Jika terjadi penurunan nilai aset } \\
\text { zakat non kas, maka jumlah } \\
\text { kerugian yang di tanggung } \\
\text { diperlakukan sebagai pengurang } \\
\text { dana amil bergantung pada } \\
\text { penyebab kerugian tersebut. } \\
\text { c. Penurunan nilai aset zakat diakui } \\
\text { sebagai a). Pengurangan dana } \\
\text { zakat, jika tidak disebabkan oleh } \\
\text { kelalaian amil, b). Kerugian dan } \\
\text { pengurangan dana amil, jika di } \\
\text { sebabkan oleh kelalaian amil } \\
\text { Infaq dan sedekah } \\
\text { d. Infaq/sedekah yang diterima } \\
\text { diakui sebagai penambahan dana } \\
\text { infaq/sedekah dengan tujuan } \\
\text { pemberi infaq/sedekah sebesar } \\
\text { jumlah yang di terima, jika dalam } \\
\text { bentuk kas dan nilai wajar jika } \\
\text { dalam bentuk non kas }\end{array}$ \\
\hline
\end{tabular}




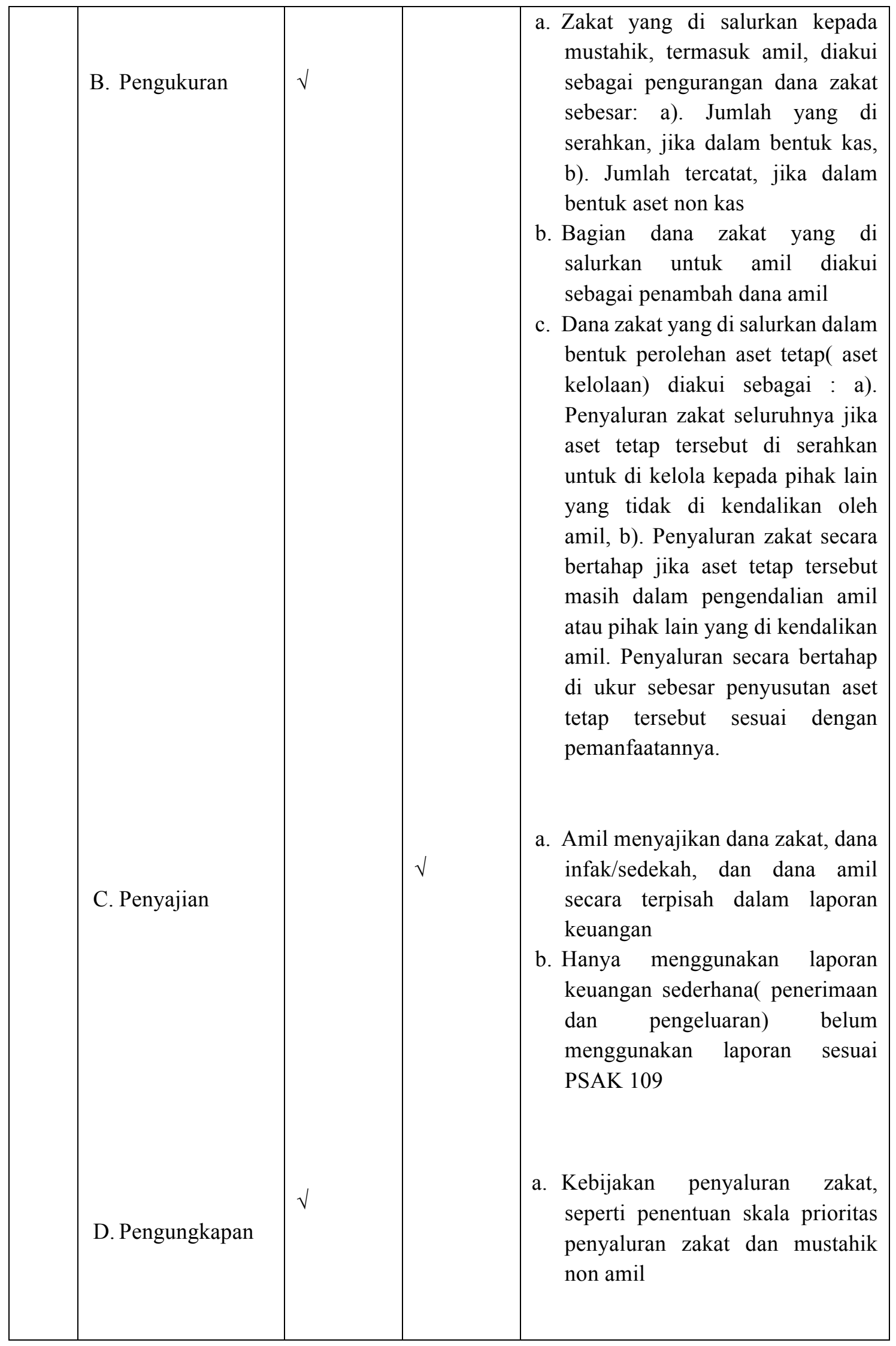




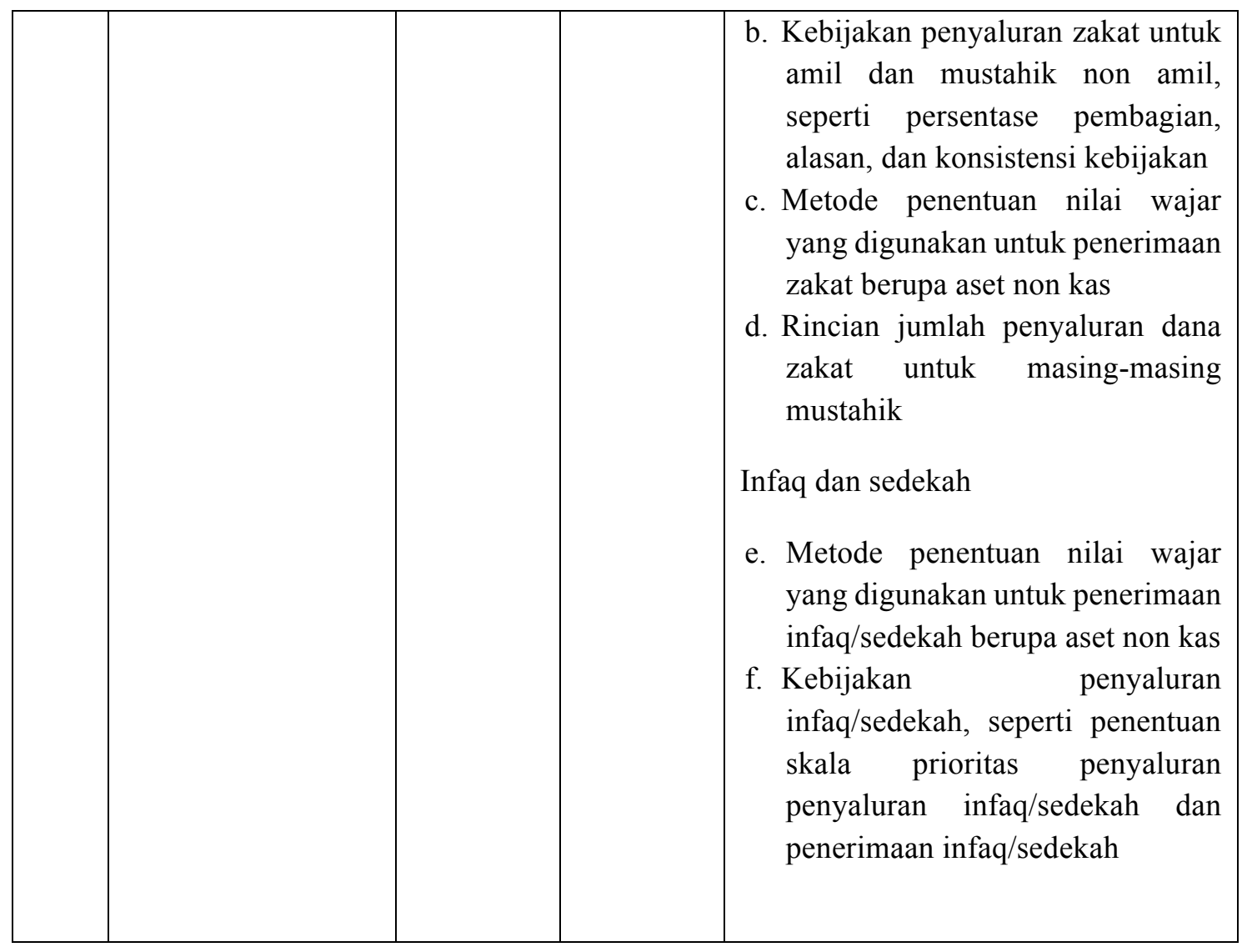

\section{KESIMPULAN DAN SARAN}

Berdasarkan hasil wawancara terstruktur yang telah di lakukan kepada Ketua, wakil ketua 1 dan wakil ketua 2 Baznas Kab. Majene yang mengakomodir pertanyaan terstruktur . sebanyak 13 pertanyaan, dan disempurnakan dengan wawancara tidak terstruktur. Dengan wawancara yang di lakukan baik secara terstruktur ataupun tidak terstruktur dapat di simpulkan bahwa Penerapan Akuntansi ( PSAK 109 Zakat, Infa/sedekah) tahun 2014-2016 belum sepenuhnya mengacu kepada PSAK 109, dimana di dalamnya terdiri dari pengakuan, pengukuran, penyajian, dan pengungkapan. Hal ini bisa dilihat dari penyajian laporan keuangan Baznas Kab. Majene tahun 2014-2016 yang belum di sajikan sesuai dengan aturan yang ada. Adapun saran-saran dari hasil penelitian ini

\section{Bagi peneliti}

a. Dapat memberikan data yang lebih lengkap mengenai ruang lingkup penelitian 
b. Dapat berkontribusi kedepannya dari aspek pengelolaan keuangan Baznas Kab. Majene dalam rangka implementasi laporan keuangan sesuai PSAK 109

2. Bagi Objek penelitian( Baznas Kab. Majene)

Implementasi sepenuhnya PSAK 109 untuk Baznas yang lebih baik kedepannya

3. Bagi peneliti selanjutnya

Peneliti selanjutnya bisa menyempurnakan dan menghubungkan dengan penerapan PSAK 109 zakat, infaq/ sedekah yang akan berpengaruh pada tingkat kesejahteraan masyarakat

\section{DAFTAR PUSTAKA}

Dewan Standar Akuntansi Keuangan. 2008. Exposure draft PSAK No. 109 Pernyaan standar akuntansi keuangan Akuntansi zakat dan infak/Sedekah

Didin Hafidhuddin. (2007). Agar harta Berkah dan Bertambah. Jakarta: Gema Insani Press.

Dwi Martani, Sylvia Veronika NPS, Ratna Wardhani, Aria Farahmita, Edward Tanujaya. (2012). Akuntansi Keuangan Menengah Berbasis PSAK. Buku 1. Jakarta: Salemba Empat.

Engkoswara \& Aan Komariah. 2011. Administrasi Pendidikan. Bandung: Alfabeta.

Kementerian Agama RI. (2012). Panduan Organisasi Lembaga Amil Zakat. Jakarta: Direktorat Jenderal Bimbingan Masyarakat Islam Direktorat Pemberdayaan Zakat.

Kementerian Agama RI. (2012). Petunjuk Teknis Evaluasi dan Pelaporan LPZ.Jakarta: Direktorat Jenderal Bimbingan Masyarakat Islam Direktorat Pemberdayaan Zakat.

Kementerian Agama RI. (2012). Pedoman Pengawasan Lembaga Lembaga Amil Zakat. Jakarta: Direktorat Jenderal Bimbingan Masyarakat Islam Direktorat Pemberdayaan Zakat.

Nurhayati, S. (2009). Akuntansi Syariah di Indonesia. Jakarta: Salemba Empat.

Pahala Nainggolan. (2007). Akuntansi Keuangan Yayasan dan Lembaga Nirlaba Sejenis. Jakarta: PT. RajaGrafindo Persada. 
Peraturan Pemerintah Nomor 14 Tahun 2014 Tentang Pelaksanaan UndangUndang Nomor 23 Tahun 2011 Tentang Pengelolaan Zakat.

Pernyataan Standar Akuntansi Keuangan Nomor 109 Tentang Akuntansi Zakat, Infak dan Sedekah.

Teten Kustiawan, dkk. (2012). Pedoman Akuntansi Amil Zakat (PAAZ) Panduan implementasi Penyusunan laporan Keuangan Berbasis PSAK 109. Jakarta: Forum Zakat

Undang-Undang Republik Indonesia Nomor 23 Tahun 2011 Tentang Pengelolaan Zakat 
